\title{
Characterization of an amorphous indium tin oxide (ITO) film on a polylactic acid (PLA) substrate
}

\author{
U SAEED $^{1, *}$ (D, M SH ABDEL-WAHAB ${ }^{2}$, V K SAJITH $^{2}$, M S ANSARI ${ }^{2}$, A M ALI ${ }^{1}$ \\ and H A AL-TURAIF ${ }^{1}$ \\ ${ }^{1}$ Department of Chemical and Materials Engineering, Faculty of Engineering, King Abdul Aziz University, Jeddah 21589, \\ Kingdom of Saudi Arabia \\ ${ }^{2}$ Center of Nanotechnology, King Abdul Aziz University, Jeddah 21589, Kingdom of Saudi Arabia \\ *Author for correspondence (usman144de@yahoo.com)
}

MS received 11 June 2018; accepted 19 December 2018; published online 30 May 2019

\begin{abstract}
The study presents the deposition of nanostructured indium tin oxide thin films with thicknesses of 10, 30 and $50 \mathrm{~nm}$ on the polylactic acid (PLA) substrate by sputtering at $30^{\circ} \mathrm{C}$. The absence of ITO peaks on the X-ray diffraction patterns confirms the amorphous state of ITO films and the X-ray photoelectron spectroscopy spectrum validates the deposition of ITO films on the PLA substrate. The results of atomic force microscopy of films exhibit variation in the average roughness of $0.3-1.5 \mathrm{~nm}$ when the thickness is increased. It was examined that optical transmission is dependent on the thickness of films which varies from 78 to $87 \%$ in the visible spectrum of 400-700 nm and the energy band gap varies from 3.95 to $4.02 \mathrm{eV}$. The films exhibit the low sheet resistance which is due to the formation of oxygen vacancies and dangling bonds. An increase in transmittance enhances the FOM of the ITO films on the PLA substrate.
\end{abstract}

Keywords. Sputtering; polylactic acid (PLA); indium tin oxide (ITO); UV-Visible spectroscopy; atomic force microscopy (AFM).

\section{Introduction}

The demand for flexible displays can rise up to $250 \%$ in the year of 2020 leading to an enormous potential for the formation of a new class of products [1]. The high performance and light weight polymers are increasingly interesting as substrates in the manufacturing of display devices. The polymers which can be applied as substrates have many fascinating characteristics when compared to glass substrates such as they are robust, light weight, thin and flexible [2]. Moreover, polymer substrates provide displays that are more resistant to impact damage and valuable in developing low cost high performance products. The polymers such as polyethylene terephthalate (PET), polytetrafluoroethylene (PTFE), polyethylene naphthalate (PEN), polyimide (PI) and polycarbonate (PC) are the predominantly used substrates. The aforementioned polymer PI shows high performance with excellent mechanical properties and ease of fabrication [3] whereas PEN, PC and PET have significantly less mechanical properties but offer substantial optical characteristics in comparison with PI [4]. Nowadays, the manufacturing of materials used for the reduction in environmental pollution must be ecofriendly and biodegradable. Among the other biodegradable polymers polylactic acid (PLA) has gained interest in many applications as a leading environmentally amiable polymer $[5,6]$. PLA has good optical properties especially transparency and excellent mechanical properties. Due to these features,
PLA can be used as a substrate material for display devices. On the other hand, zinc oxide, impurity doped indium and tin oxide are used as transparent oxide thin films [7]. In these films, indium tin oxide (ITO) has high optical transmittance and comparatively little electrical resistivity of $1-4 \times 10^{-4}$ $\Omega \mathrm{cm}$ in the $400-700 \mathrm{~nm}$ range of the spectrum. These characteristics make ITO a preferable choice for many applications such as flexible portable displays [8] and can be easily fabricated at relatively high substrate temperatures [9] which limit the applications in certain areas. Many times ITO has been deposited on the glass substrate and currently manufacturers have deposited ITO on polymer substrates [10]. ITO has been deposited successfully for a wide range of polymers such as thermoplastic polymethyl methacrylate, PC, PTFE (Teflon) and PET [11-13] but ITO is an expensive material so the cost effectiveness is greatly critical.

Many times before the ITO thin films has been deposited on different types of polymer substrates at low temperature by using variety of processes including sol-gel, radio-frequency sputtering, spray deposition, chemical vapour deposition and electron beam evaporation [14-17]. Regarding these techniques, numerous issues have to be resolved during deposition of ITO on the polymer substrate as specifically these polymers are highly sensitive to temperature. This means that low temperature deposition is required in order to avoid the degradation of the polymer substrate [18]. During these attempts the detailed studies of the ITO film on the polymer substrate 
have been performed which includes adhesion, structural, electrical and optical properties [19]. In this research, the ITO films with thicknesses of 10,30 and $50 \mathrm{~nm}$ were deposited on the PLA substrate at $30^{\circ} \mathrm{C}$ below $57^{\circ} \mathrm{C}$ (glass transition temperature, $T_{\mathrm{g}}$, of PLA) using the DC sputtering technique. One of the important aspects of this study is the use of PLA which was never been applied before as the substrate material for display devices. The obtained ITO thin films on the PLA substrate are characterized by using $\mathrm{X}$-ray diffraction (XRD), atomic force microscopy (AFM), $\mathrm{X}$-ray photoelectron spectroscopy (XPS), four point probe and an UV-Visible spectrometer. Also, the studies of structural, morphological, electrical and optical properties are made.

\section{Experimental}

A gram of PLA 2003D (NatureWorks, USA) granules was dissolved in $30 \mathrm{ml}$ solution of 50:50 concentrations of chloroform and acetone. The solution was stirred in a magnetic stirrer for four hours. The stirred solution was spin coated on the glass substrate using OPTI Coat (ATM Vision, Germany) with a rotational velocity of $3000 \mathrm{rpm}$. The obtained coated product was placed in iso-propyl alcohol to remove PLA films from the glass substrate and then it was dried for $24 \mathrm{~h}$. Prior to the deposition of the films the PLA substrates were successively ultrasonically cleaned in acetone to remove surface contaminations in order to improve the adhesion between the ITO and PLA substrate. The ITO thin films with thicknesses of 10,30 and $50 \mathrm{~nm}$ were created on the PLA substrate by DC/RF sputtering (Syskey, Taiwan). The deposition was carried out at $30^{\circ} \mathrm{C}$ and $205 \mathrm{~cm}^{3}$ of argon gas was controlled through a mass flow meter. The applied DC power was $200 \mathrm{~W}$ whereas the gap between the substrate and target was $14 \mathrm{~cm}$. The pressure during the process was $5 \times 10^{-3}$ torr and the base pressure of the sputtering system was $9 \times 10^{-6}$ torr.

Ellipsometry (Horiba UVSEL, France) has been used to determine the thickness of PLA and ITO thin films which were about $200 \mu \mathrm{m}, 10,30$ and $50 \mathrm{~nm}$. These obtained results were also confirmed by a surface profiler (Dektak, BrukerGermany). XRD (Ultima-IV; Rigaku, Japan) was used to determine the structure of the films with the $\mathrm{CuK} \alpha$ source at a wavelength of $0.15406 \mathrm{~nm}$. The field emission scanning electron microscope (FESEM, JEOL JSM 7600F, Japan) and atomic force microscope (SPM PROBE VT AFM XA 50/500 Omicron $\mathrm{GmbH}$, Germany) with a scan speed of $1250 \mathrm{~nm} \mathrm{~s}^{-1}$ and a force set point of $1.5 \mathrm{nN}$ in contact mode were used to describe the surface morphology. XPS (K SPECS GmbH, Germany) was utilized to further quantify and detect the elemental composition of the sample by using a base pressure of $1 \times 10^{-8}$ mbar. A dual anode non-monochromatic $\mathrm{MgK} \alpha$ $\mathrm{X}$-ray source was employed to irradiate the surface of the sample with $13.5 \mathrm{kV}$ and $150 \mathrm{~W}$. The UV-Visible spectrometer (Perkin Elmer Lambda 750) with a scan speed of $266.75 \mathrm{~nm}$ $\min ^{-1}$ has been used to examine the optical properties of the ITO thin films. The adhesion test was carried out on the films as per the ASTMB905 standard. By employing the transparent adhesive tape the Scotch Tape Peel Off test was performed on the deposited thin film on the PLA substrate. The tape was applied to the ITO deposited PLA film and was peeled off from it after few minutes. The four-point contact probe (DUORES, Napson Corporation, Japan) was utilized to measure the resistivity and sheet resistance of the ITO films. The obtained data of sheet resistance have an accuracy of less than $\pm 0.5 \%$. The bending test was carried out by loading the rectangular sample in the Instron machine. Each ITO film was clamped and subjected to compressive stress with a bending diameter of 40, 30, 20, 10, 5, 2 and $0.30 \mathrm{~mm}$.

\section{Results and discussion}

Figure 1 shows the XRD pattern of the PLA substrate and the $30 \mathrm{~nm}$ ITO film on the substrate. The diffraction patterns were observed at about $2 \theta=16.7521,19.0402,22.4372$ and $31.5916^{\circ}$ and examined that the full width at half maximum is smaller. These obtained characteristics are attributed to the PLA substrate. Furthermore, it is perceived that there are no additional diffraction peaks in the XRD patterns demonstrating the amorphous character of ITO films on the PLA substrate. Similar diffraction patterns have been observed for 10 and $50 \mathrm{~nm}$ films. The acquired amorphous structure is in line with the accomplishments by You et al [20] and Hao et al [21] as they deposited the ITO films on polyethersulfone and PET substrates. It implies that the low temperature of the substrate during the sputtering process prevents the crystallization of the ITO films leading to formation of the amorphous structure.

Figure 2 presents the XPS spectrum which determines the presence of ITO element on the PLA substrate. Figure 2a exhibits the XPS peaks of PLA having appropriate variable

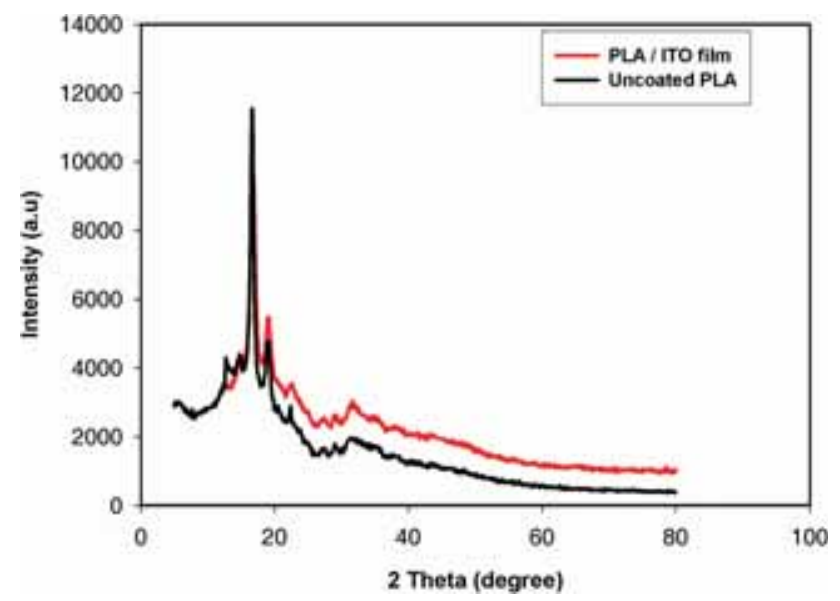

Figure 1. XRD pattern of the PLA substrate and the $30 \mathrm{~nm}$ ITO film on the PLA substrate. 

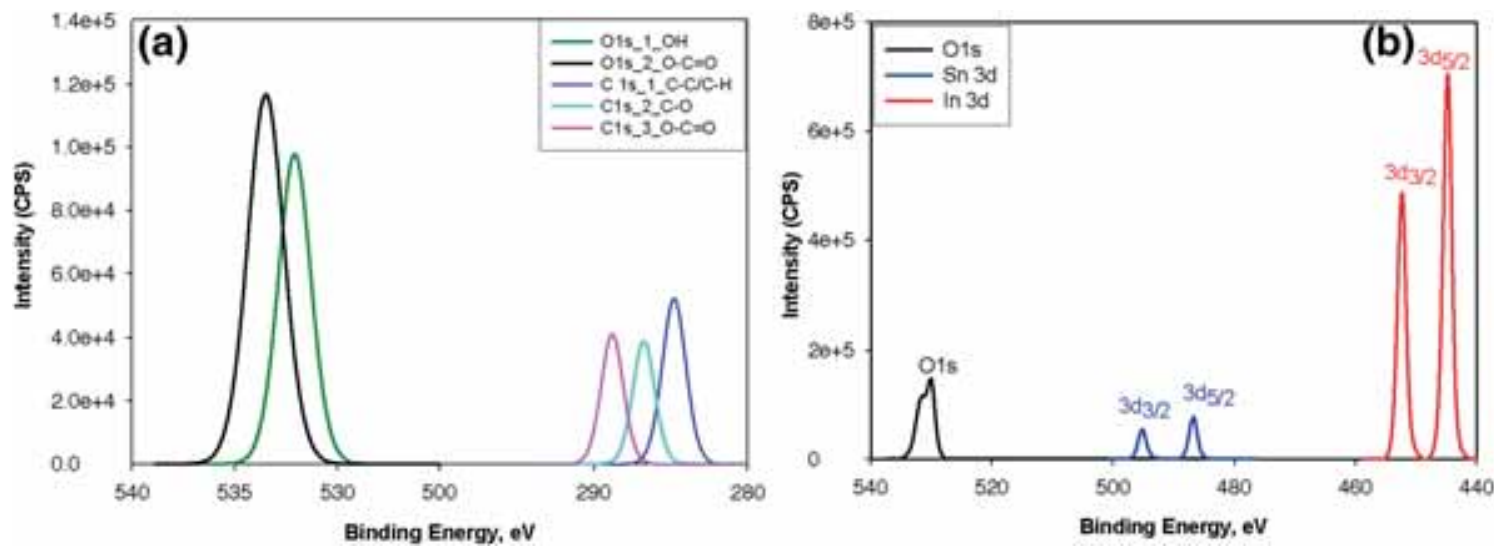

Figure 2. XPS spectra of (a) PLA and (b) $30 \mathrm{~nm}$ ITO film on the PLA substrate.

Table 1. XPS peaks with binding energy (BE) and bond type of $\mathrm{C} 1 \mathrm{~s}$ and $\mathrm{O} 1 \mathrm{~s}$ regions.

\begin{tabular}{|c|c|c|c|}
\hline \multicolumn{2}{|l|}{ PLA } & \multicolumn{2}{|c|}{ ITO films } \\
\hline Components & $\mathrm{BE}, \mathrm{eV}$ & Components & $\mathrm{BE}, \mathrm{eV}$ \\
\hline O1s_1_OH ${ }^{-}$ & 532.07 & O1s_1_O ${ }^{2-}$ & 529.94 \\
\hline O1s_2_O-C $=\mathrm{O}$ & 533.48 & $\operatorname{In} 3 d_{5 / 2} \_1 \_I^{3+}$ & 444.79 \\
\hline $\mathrm{C} 1 \mathrm{~s} \_1$ _CC$-\mathrm{C} / \mathrm{C}-\mathrm{H}$ & 284.8 & $\operatorname{In} 3 \mathrm{~d}_{3 / 2}{ }_{2}{ }_{2} \mathrm{In}^{3+}$ & 452.34 \\
\hline C1s_2_C-O & 286.75 & $\mathrm{Snd}_{5 / 2 \_1 \_\mathrm{Sn}^{4+}}$ & 486.77 \\
\hline $\mathrm{C} 1 \mathrm{~s} \_3 \_\mathrm{O}-\mathrm{C}=\mathrm{O}$ & 288.82 & $\mathrm{Snd}_{3 / 2}{ }_{2} \mathrm{Sn}^{4+}$ & 495.18 \\
\hline
\end{tabular}

intensities of the functional groups correspond to $\mathrm{C} 1 \mathrm{~s}$ and $\mathrm{O} 1 \mathrm{~s}$ regions. The PLA is formed by covalent bonding of hydrogen, oxygen and carbon shown in table 1 . The $\mathrm{C}-\mathrm{O}, \mathrm{O}-\mathrm{C}=\mathrm{O}$ and $\mathrm{C}-\mathrm{C} / \mathrm{C}-\mathrm{H}$ bonds at $286.75,288.8$ and $284.8 \mathrm{eV}$ are present in the PLA substrate with their peak positions in the $\mathrm{C} 1 \mathrm{~s}$ region. Simultaneously, $\mathrm{OH}$ and $\mathrm{O}-\mathrm{C}=\mathrm{O}$ bonds are present at 532.07 and $533.48 \mathrm{eV}$ in the $\mathrm{O} 1 \mathrm{~s}$ region. The obtained results in the molecular binding energies (BEs) of PLA are in agreement with the finding of Vergne et al [22]. Figure $2 \mathrm{~b}$ shows that the measured elements in the ITO film of $30 \mathrm{~nm}$ are indium $\left(\operatorname{In} 3 d_{3 / 2}\right.$ and $\left.\operatorname{In} 3 d_{5 / 2}\right)$, tin $\left(\operatorname{Sn} 3 d_{3 / 2}\right.$ and $\left.\operatorname{Sn} 3 d_{5 / 2}\right)$ and oxygen (O1s). In all ITO films the XPS peaks of $\operatorname{In} 3 \mathrm{~d}_{3 / 2}, \operatorname{In} 3 \mathrm{~d}_{5 / 2}$, $\operatorname{Sn} 3 \mathrm{~d}_{3 / 2}, \mathrm{Sn}_{3} \mathrm{~d}_{5 / 2}$ and O1s appear at 452.35, 444.75, 495.15, 486.7 and $530.05 \mathrm{eV}$, respectively, as also shown in table 1 . There were no chemical shift in BEs and similar results were observed with 10 and $30 \mathrm{~nm}$ ITO films. These results are similar to the other surface characterization techniques of ITO [23]. However, the absence of any other elemental peak in XPS spectra indicates the absence of contamination which is required to improve the adhesion between the PLA substrate and ITO films.

Figure 3 presents the cross section of 10,30 and $50 \mathrm{~nm}$ ITO films deposited on the PLA substrate. Figure $4 \mathrm{a}-\mathrm{c}$ demonstrates that there were no certain morphologies except inhomogeneity of the surface which exists in the ITO films and distributes evenly while figure $4 \mathrm{~d}$ presents the digital image of PLA and 10 and $50 \mathrm{~nm}$ ITO films. Moreover, it was observed that there were no significant changes after the peel off test in the surface morphology of the deposited film suggesting that the bonding was adequately strong. The results of AFM for the PLA substrate and 30 and $50 \mathrm{~nm}$ ITO films are presented in figure 5. The quantitative analysis [18] of the surface morphology is shown in table 2. The surface roughness (Sq) values of $0.375428,0.5123,0.736082$ and $1.3284 \mathrm{~nm}$ were determined for the PLA substrate, 10, 30 and $50 \mathrm{~nm}$ ITO films deposited at $30^{\circ} \mathrm{C}$ respectively. Whereas, 0.50011 , $0.72321,0.948964$ and $1.66095 \mathrm{~nm}$ are attributed to the PLA substrate, 10, 30 and $50 \mathrm{~nm}$ ITO films with respect to the root mean square $(\mathrm{Sq})$. The analysis demonstrates that the root mean square $(\mathrm{Sq})$, kurtosis $(\mathrm{Sku})$, average roughness $(\mathrm{Sa})$ and skewness (Ssk) are significantly dependent on the cluster size of the films and increase with the corresponding increase in the film thickness. However, a slightly small value of the PLA substrate exposes the possibility of good adhesion with ITO films.

Figure 6a presents the transmittance spectra of ITO films with various thicknesses on the PLA substrate. It is found that the transmittance of PLA in the visible region varies from $82 \%$ at $400 \mathrm{~nm}$ to $95 \%$ at $700 \mathrm{~nm}$ and is higher than the ITO films. The figure shows that the transmission of the ITO films is dependent on the thickness of the film and decreases with the increase in the film thickness. The developed ITO films have their maximum transmittance at a wavelength of about $700 \mathrm{~nm}$. Moreover, the transmission decreases from 87 to $65 \%$ with the increase in the thickness of the ITO film from 10 to $50 \mathrm{~nm}$. This decrease is due to the inhomogeneity of the surface due to an increase in the thickness that leads to the scattering of light and might be due to the decrease in the carrier concentration which blocks the energy [24]. Figure 6b shows the reflection spectra of the ITO films. There is a noticeable reflection with the increase in the thickness and is consistent with the decrease in transmittance. 


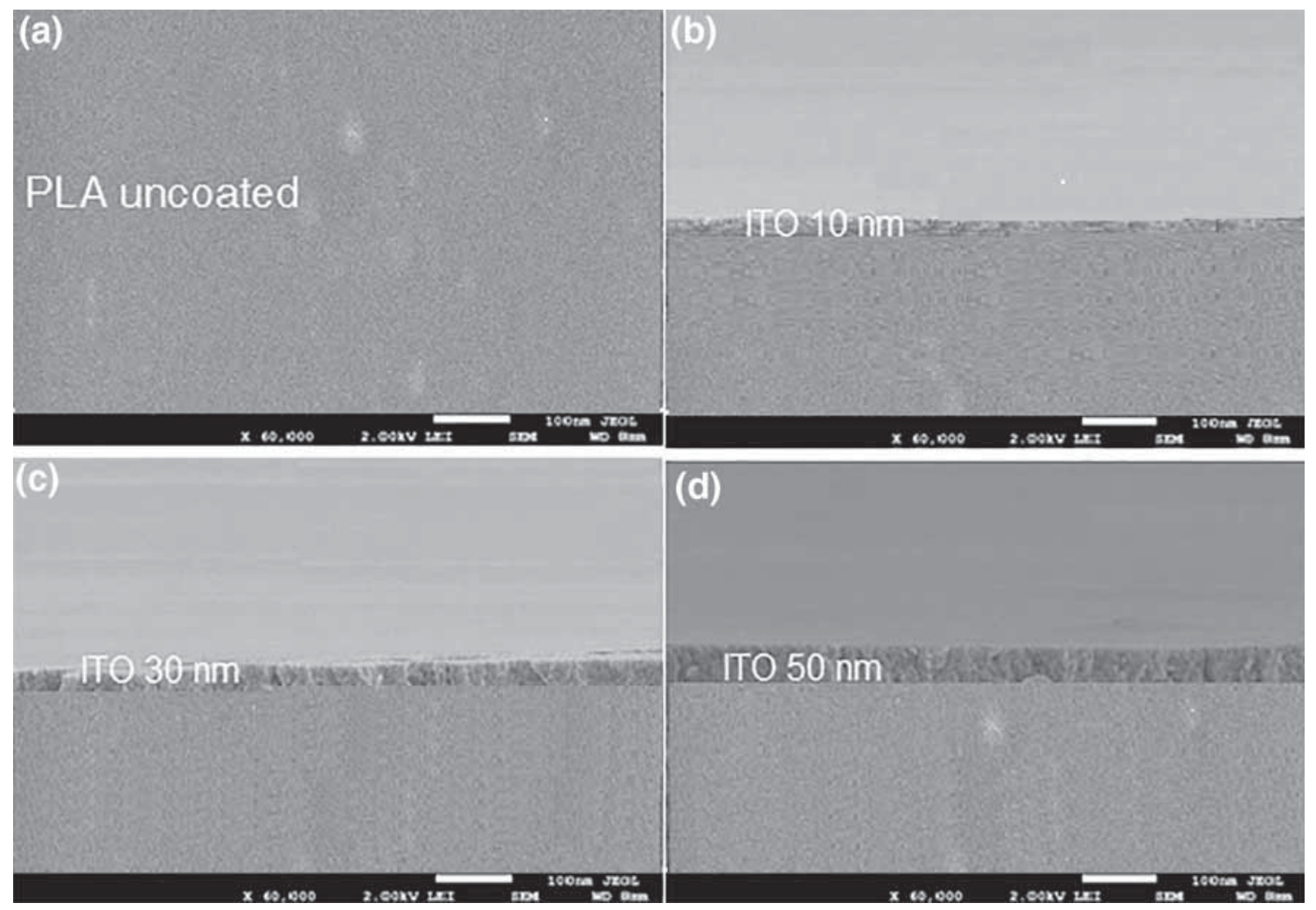

Figure 3. SEM section images of (a) PLA, (b) $10 \mathrm{~nm}$ ITO film, (c) $30 \mathrm{~nm}$ ITO film and (d) $50 \mathrm{~nm}$ ITO film.

The average reflectivity value of $35 \%$ in the $50 \mathrm{~nm}$ film is higher when compared to $15 \%$ of the $10 \mathrm{~nm}$ film in the visible spectrum. This higher reflectivity is attributed to the increase in the quantitative value of the morphological AFM results.

The absorption coefficient of the films is determined by the equation given below [25]:

$$
\alpha=\left(\frac{1}{d}\right) \ln \left(\frac{1}{T}\right),
$$

where $T$ is the transmittance and $d$ is the thickness of the films.

The influence of the thickness of ITO films on the absorption coefficient is shown in figure $7 \mathrm{a}$. The visible spectrum of the wavelength in the range of 400-700 $\mathrm{nm}$ shows that the absorption coefficient $\alpha$ varies from $0.53-0.28$ in the $10 \mathrm{~nm}$ film to $0.75-0.39$ in the $50 \mathrm{~nm}$ film. The low value of $\alpha$ presents that the ITO films do not act as the absorbing medium because photon energy $(h v)$ is lower than the band gap energy $\left(E_{\mathrm{g}}\right)$ in the visible spectrum. This concludes that the lower value of the photon energy is essential for nonabsorbent and transparent films. However, a slight rise in the absorption coefficient by enlarging the film thickness can be attributed to the root mean square of the films.
The extinction coefficient $(k)$ values of ITO films were determined by using the equation

$$
k=\frac{\alpha \lambda}{4 \pi}
$$

where $\alpha$ is the absorption coefficient and $\lambda$ is the wavelength.

The results are shown in figure $7 \mathrm{~b}$. The $k$ values of ITO films in the visible spectrum are in the range of 0.28 in $10 \mathrm{~nm}$ to 0.49 in $50 \mathrm{~nm}$ film. The low $k$ values exhibit that the films are not strong absorbing medium as is also indicated by $\alpha$. These $k$ values are completely dependent on the thickness and gradually increases with the ITO film. This slight increase in the extinction coefficient $(k)$ is related to the formation of defects attributed to the root mean square $(\mathrm{Sq})$ and average roughness $(\mathrm{Sa})$ of the ITO films.

The refractive indices of the films in the visible range were calculated by reflectance spectra and presented in figure $7 \mathrm{c}$. It is found that the refractive indices show the variations with the wavelength and increases with the ITO film thickness. The $50 \mathrm{~nm}$ ITO film has the highest refractive index of 2.36 in comparison with the $10 \mathrm{~nm}$ film which has the least refractive index of 1.95. The thicker film is denser than the thinner one thus reducing the velocity of light and increasing the reflectivity leading to the increase in the refractive index of the 

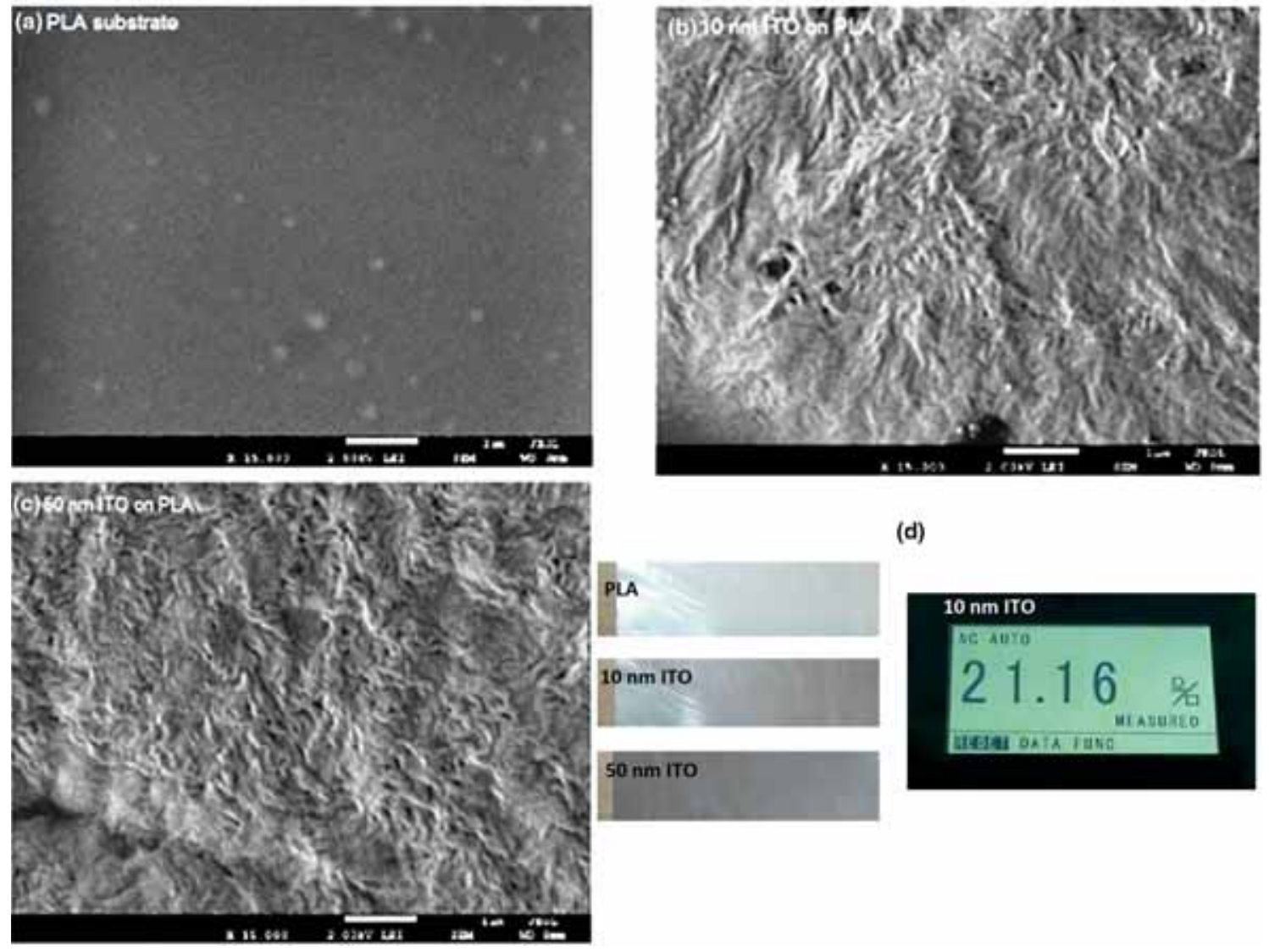

(d)

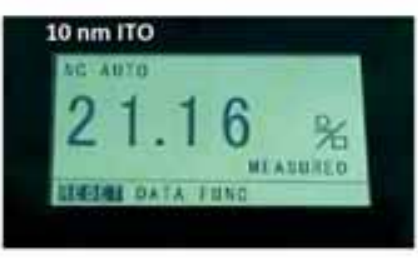

Figure 4. SEM surface images of (a) PLA, (b) $30 \mathrm{~nm}$ ITO film, (c) $50 \mathrm{~nm}$ ITO film and (d) digital image of PLA, $10 \mathrm{~nm}$ ITO film, $50 \mathrm{~nm}$ ITO film and sheet resistance of the $10 \mathrm{~nm}$ film.

film. This increase in the refractive index might be due to the short-range order in thicker films as disorder decreases with increasing film thickness.

The optical band gap $\left(E_{\mathrm{g}}\right)$ values were established by using Tauc's equation (3) [25] as shown in figure 8a

$$
\alpha h v=A\left(h v-E_{\mathrm{g}}\right)^{m}
$$

where $\alpha$ is the absorption coefficient, $h v$ is the photon energy, $A$ is a parameter proportional to the probability of electron transition between empty and occupied states, and exponent $m$ describes the state of the electronic transition such as $m=$ $1 / 2$ and $3 / 2$ correspond to forbidden and allowed transitions, respectively.

The direct nature of the band-to-band transitions of the film is confirmed by the linear portions of the plot near the band edge whereas the $E_{\mathrm{g}}$ values are obtained by extrapolating the liner portion of the curve by assuming a direct transition. The optical band gap is an intrinsic property of a material and should not be affected by the film thickness but we found that there is a nominal increase in the optical band gap from 3.95 to $4.02 \mathrm{eV}$ with the increase in the film thickness as shown in figure $8 \mathrm{~b}$. The increase in
$E_{\mathrm{g}}$ is due to dependence of the absorption coefficient on the film thickness. The occurrence of a narrow band gap might be due to free carriers and ionized impurities. Similar observation with the band gap energy from 3.5 to 4.30 $\mathrm{eV}$ was previously reported by Thirumoorthi and Prakash [26] and Kim and Gilmore [27] but the presented results are on the higher side of the optical band gap. The difference in our results might be due to the dissimilarity in the crystalline and amorphous structure of the deposited ITO films.

The resistivity and sheet resistance of the ITO thin films on the PLA substrate are shown in table 3. The resistivity increases from $3.85 \times 10^{-3}$ to $1.98 \times 10^{-3} \Omega \mathrm{cm}$ with the increase in the ITO film thickness. The higher thickness of ITO affects the surface roughness as shown in the AFM results (figure 5) indicating the increase in resistivity. Also, the outcome of the tests presents that the increase in the ITO film thickness increases the density and compactness which leads to high defects and low conductivity. Table 3 presents the sheet resistance which decreases from 21.16 to $19.84 \Omega \mathrm{sq}^{-1}$ with the increase in the film thickness and the digital image of the sheet resistance of the $10 \mathrm{~nm}$ ITO film using a four-point contact probe (DUORES) 


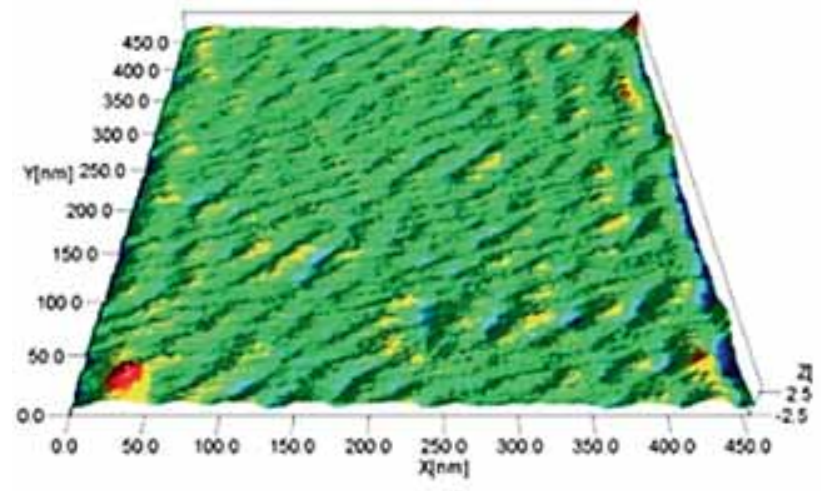

(a)

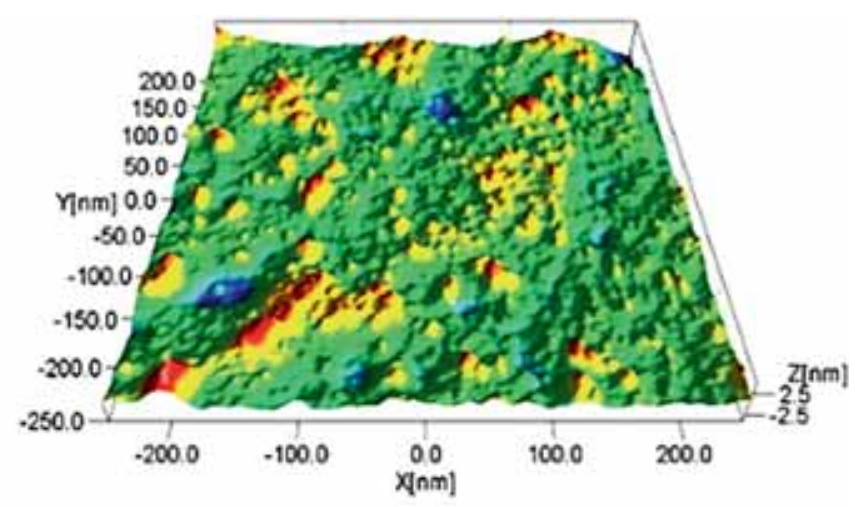

(b)

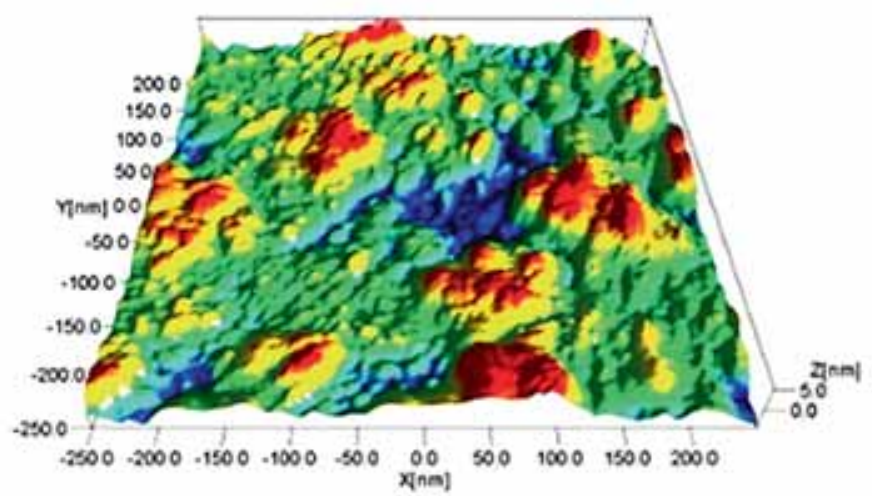

(c)

Figure 5. AFM images of (a) PLA, (b) $30 \mathrm{~nm}$ ITO film and (c) $50 \mathrm{~nm}$ ITO film.

Table 2. Quantitative data of the surface morphology by AFM.

\begin{tabular}{llllll}
\hline & \multicolumn{2}{c}{ PLA } & & \multicolumn{3}{c}{ ITO } \\
\cline { 2 - 3 } \cline { 5 - 6 } Parameter & $200 \mu \mathrm{m}$ & & $10 \mathrm{~nm}$ & $30 \mathrm{~nm}$ & $50 \mathrm{~nm}$ \\
\hline Sa, nm & 0.37542 & 0.5123 & 0.736082 & 1.32847 \\
Sq, nm & 0.50011 & & 0.72321 & 0.948964 & 1.66095 \\
Ssk & 0.26069 & & 0.3147 & 0.379983 & 0.168862 \\
Sku & 2.34129 & 2.53721 & 2.78547 & 2.84257 \\
\hline
\end{tabular}

Sa: Average roughness, Sq: root mean square, Ssk: skewness and Sku: kurtosis.

instrument is shown in figure $4 \mathrm{~d}$. The sputtering under an argon atmosphere causes the generation of oxygen vacancies in the ITO films and daggling bonds occur in the substrates. The inclusion of oxygen vacancies provides low electrical resistivity and sheet resistance while degrade the transmission of the films. The daggling in the polymer substrate causes the oxidation of $\mathrm{Sn}-\mathrm{OH}$ groups at the interface of the substrate/film and forms the $\mathrm{Sn}-\mathrm{O}$ species. Liau et al [28] confirmed that the oxidation of $\mathrm{Sn}-\mathrm{OH}$ groups to $\mathrm{Sn}-\mathrm{O}$ species at the interface is the factor that provides the low sheet resistance and increase the ITO conductivity. The existence of $\mathrm{Sn}-\mathrm{O}$ at the interface of ITO films is another reason for low sheet resistance of our PLA/ITO films. During sputtering of ITO on polyethylene, Guillen and Herrero [29] also reported a low sheet resistance of 6-7 $\Omega \mathrm{sq}^{-1}$ of ITO in PET at room temperature due to oxygen vacancies by changing the $\mathrm{Ar} / \mathrm{O}_{2}$ partial pressure.

The effect of the ITO film thickness on the bending strain with respect to the bending diameter under compression is shown in figure 9. The PLA shows that the bending strain remains constant from 40 to $2 \mathrm{~mm}$ radius of curvature and then slightly rises to $0.30 \%$ which defines the flexibility of the substrate. The created bending strain ranges from 0.0813 to $1.25 \%$ in the $10 \mathrm{~nm}$ film and 0.0934 to $1.15 \%$ in the $50 \mathrm{~nm}$ film with a bending radius from 40 to 0.3 $\mathrm{mm}$ which is a minor variation with the increase in the film thickness. It was also noted that the considerable rise in bending strain occurs in the range of $5-0.3 \mathrm{~mm}$ bending radius. It means that the $0.4 \mathrm{~mm}$ bending radius in the films leads to $1.1 \%$ critical strain [30] which was preferable for ITO films to approximate the mechanical flexibility to function in the life cycle of the films. Moreover, the 0.4 $\mathrm{mm}$ bending radius is considered as the minimum feasible radii to avoid significant compressive stresses for the formation of cracks on the ITO film deposited on the PLA substrate. 

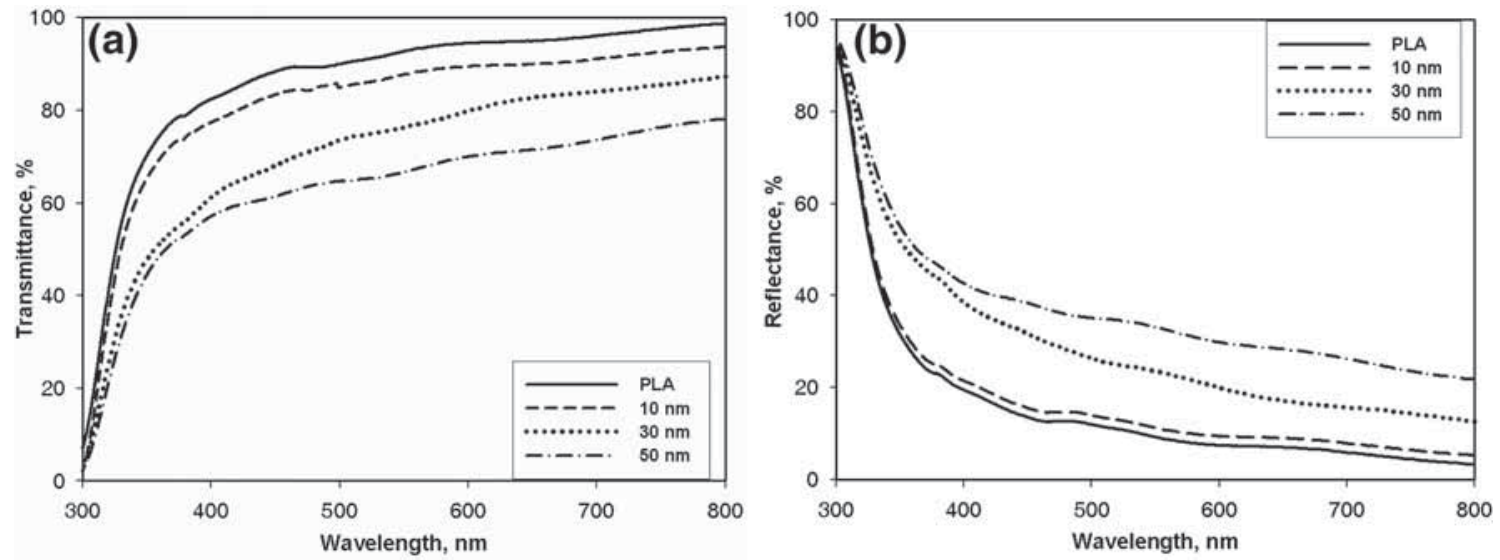

Figure 6. (a) Transmittance spectra of PLA and of ITO films on the PLA substrate. (b) Reflectance spectra of PLA and of ITO films on the PLA substrate.
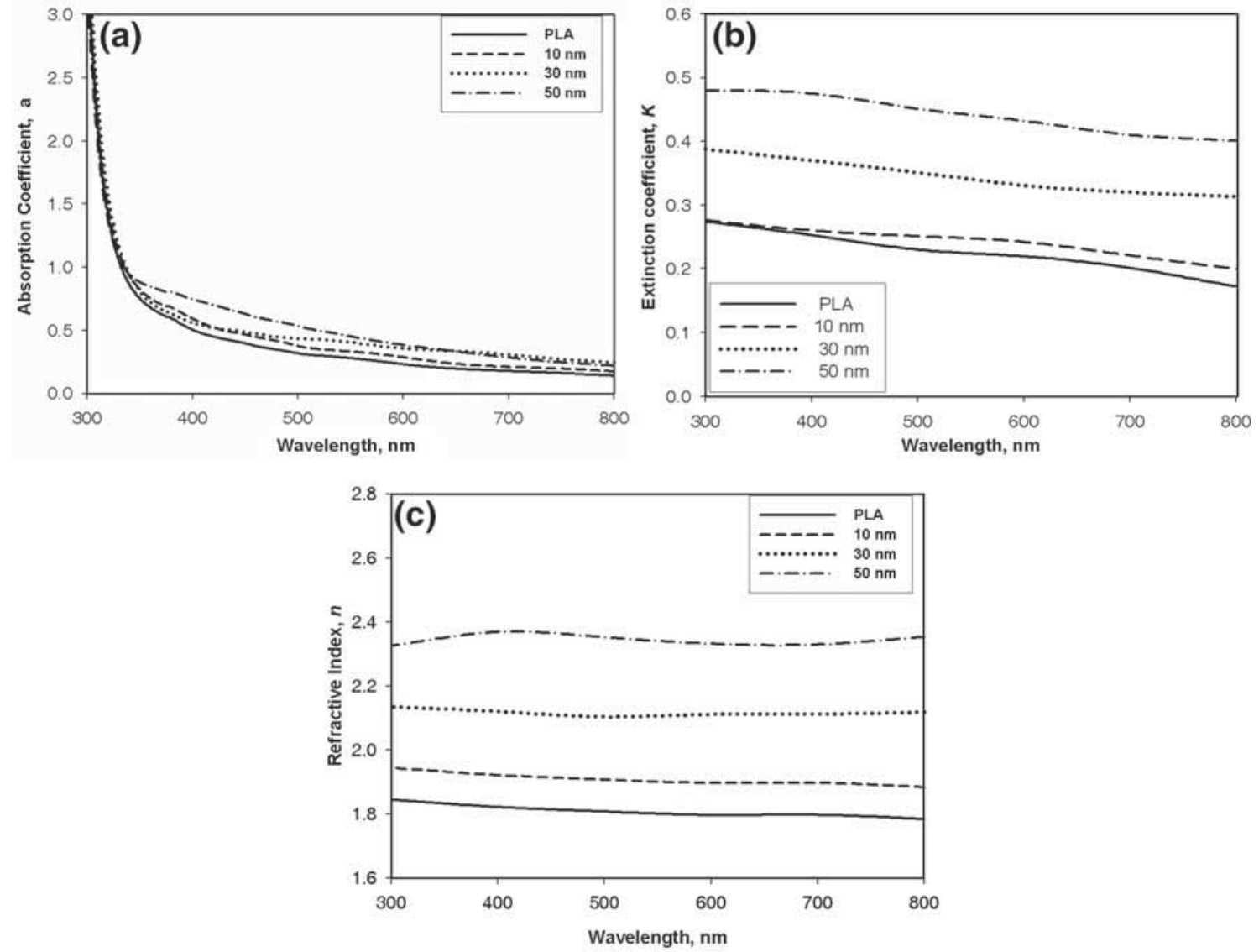

Figure 7. (a) Absorption coefficient, (b) extinction coefficient ( $k$ ) for PLA and ITO films on the PLA substrate and (c) refractive indices of the ITO films in the visible range.

The figure of merit (FOM) is estimated by using equation (4) which also clarifies the comparison between optical transmittance and electrical properties

$$
\mathrm{FOM}=\frac{T_{\mathrm{ave}}^{10}}{R_{\mathrm{Sh}}}
$$

where $T=$ optical transmittance $($ at $550 \mathrm{~nm})$ and $R_{\text {sheet }}=$ sheet resistance.

Figure 10 shows the FOM for the ITO thin films on the PLA substrate with variable thicknesses. It is observed that the FOM value decreases from $4.817 \times 10^{-2}$ to $3.313 \times 10^{-2}$ with an increase in the film thickness. The highest FOM value 

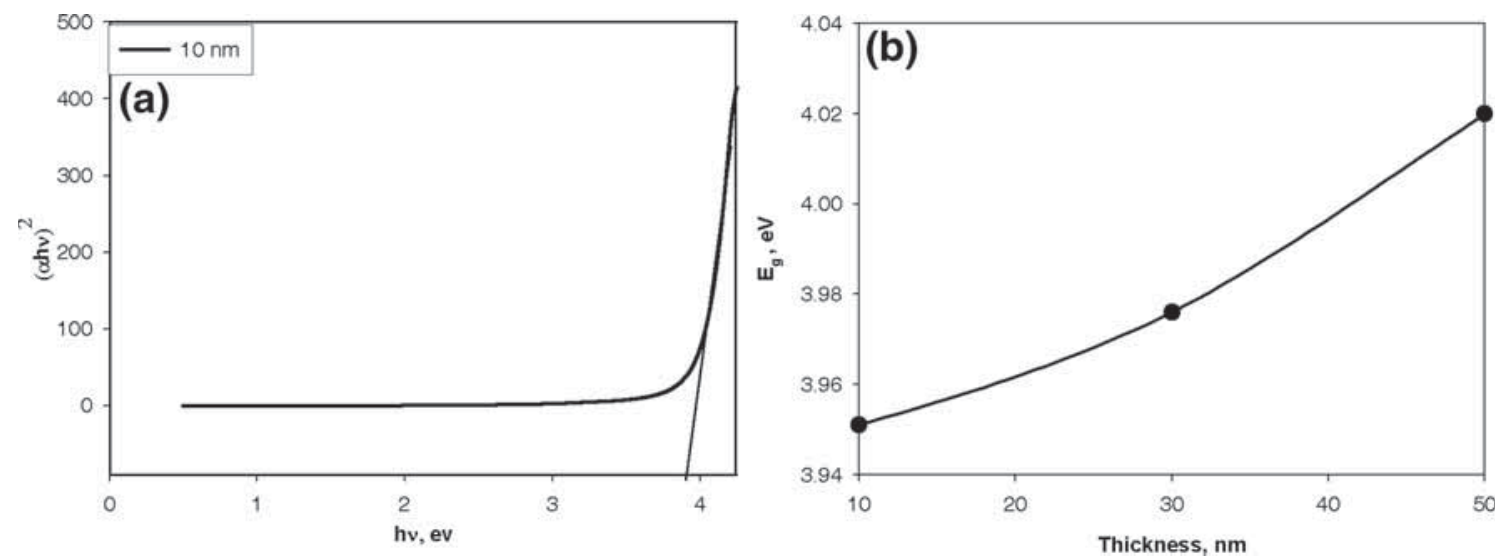

Figure 8. (a) Optical band gap of the $10 \mathrm{~nm}$ ITO film determined from $(\alpha h v)^{2} v s$. photon energy, $h v$ and (b) optical band gap variation with the thickness of ITO films.

Table 3. Electrical properties of typical ITO films deposited on the PLA substrate.

\begin{tabular}{lcc}
\hline $\begin{array}{l}\text { Film thickness } \\
(\mathrm{nm})\end{array}$ & $\begin{array}{c}\text { Resistivity, } \\
\rho(\Omega \mathrm{cm})\end{array}$ & $\begin{array}{c}\text { Sheet resistance } \\
\left(\Omega \mathrm{sq}^{-1}\right)\end{array}$ \\
\hline 10 & $3.85 \times 10^{-3}$ & 21.16 \\
30 & $2.91 \times 10^{-3}$ & 20.55 \\
50 & $1.98 \times 10^{-3}$ & 19.84 \\
\hline
\end{tabular}

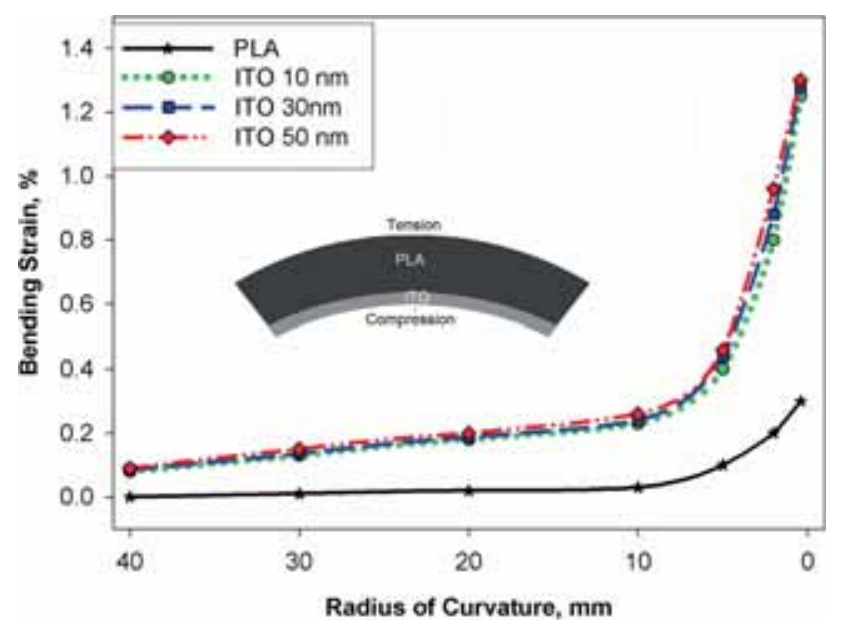

Figure 9. Bending strain with the radius of curvature.

and high optical transmittance are accomplished when the ITO film is $10 \mathrm{~nm}$. The result shows that the ITO film of $10 \mathrm{~nm}$ on the PLA substrate has the highest value of FOM which might be due to the least number of defects and minimal amorphous regions when compared to 30 and $50 \mathrm{~nm}$ ITO films.

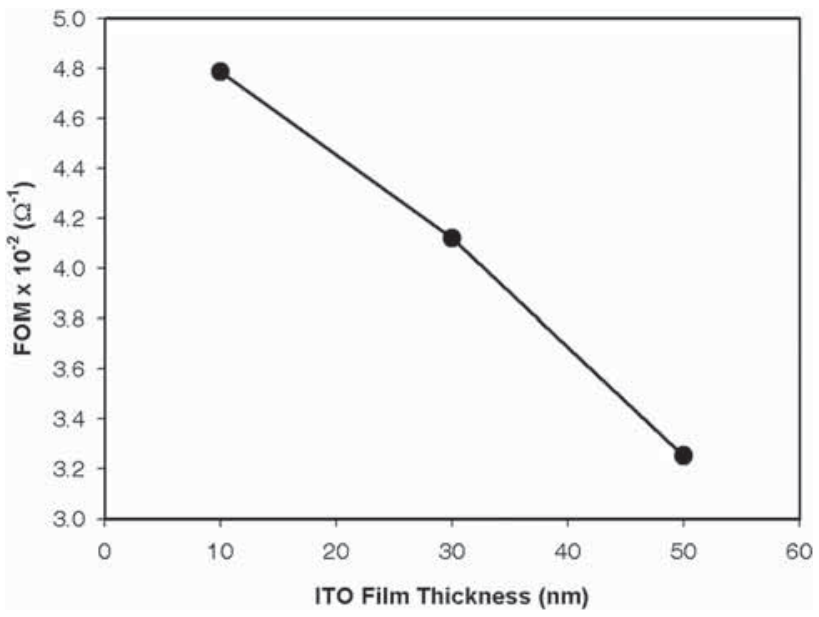

Figure 10. FOM of the ITO thin films on the PLA substrate.

\section{Conclusion}

A PLA substrate was developed by using the spin coating technique and the ITO films of variable thicknesses were deposited by DC sputtering on the PLA substrate. The effect of ITO films on the morphological, structural and optical characteristics has been studied. It was found that the ITO peaks were absent in the XRD pattern which defines the amorphous state of the films whereas the XPS data acquisition confirms the presence of ITO on the PLA substrate. The quantitative analysis by AFM revealed that the average roughness and root mean square increase with the increase in the ITO film thickness. The reduction in transmittance and low sheet resistance occurs with the increase in the thickness of the film and might be due to the formation of $\mathrm{SnO}$ species at the interface of the film under an argon atmosphere. The FOM is dependent on the thickness of the film and reduces with the increase in the thickness of the film. The FOM and transmittance values are 
relatively high with the $10 \mathrm{~nm}$ film which makes the film suitable for display devices. Moreover, the compressive stresses are formed when the ITO film bending strain reaches $1.1 \%$ and the bending radius of curvature is $0.4 \mathrm{~mm}$. This means that the curvature of the film radius should be higher than 0.4 $\mathrm{mm}$ to avoid the crack generation in the film.

\section{References}

[1] Flexible Display Market to Reach Nearly 800 Million by 2020 (Online). Available: www.technology.ihs.com

[2] West J L, Bodnar V, Kim H Y and Wonderly H 1999 IDW 99 335

[3] Suo Z, Ma E Y, Gleskova H and Wagner S 1999 Appl. Phys. Lett. 741177

[4] Gleskova H, Wagner S and Suo Z 1999 Appl. Phys. Lett. 75 3011

[5] Hutchinson M H, Dorgan J R, Knauss D M and Hait S B 2006 J. Polym. Environ. 14119

[6] Zhang J M, Tsuji H, Noda I and Ozaki Y 2004 J. Phys. Chem. B 10811514

[7] Chopra K L, Major S and Pandya D K 1983 Thin Sol. Films 1021

[8] Gessert T A, Williamson D L and Nozik A J 1991 Proc. of 3rd Intl. Conf. on InP Mater., Wales, UK, p 32

[9] Ederth J, Johnsson P, Granqvist C G, van Doorn A R, Jongerius M R and Burgard D 2003 Phys. Rev. B 6155410

[10] Buchanan M, Webb J B and Williams D F 1980 Appl. Phys. Lett. 37213

[11] Kulkarni A K, Schulz K H, Lim T S and Khan M 1997 Thin Sol. Films 1308
[12] Chiou B S and Hsieh S T 1993 Thin Sol. Films 229146

[13] Mansingh A and Vasant S V R 1988 Thin Sol. Films 16711

[14] Guo D, Ito A, Goto T, Tu R, Wang C, Shen Q et al 2013 Mater. Lett. 93179

[15] Sasani G M and Bahramian A R 2008 Mater. Lett. 62 361

[16] Nguyen T D, Pham V H, Cuong T V, Hahn S H, Kim E J, Chung J S et al 2010 Mater. Lett. 641387

[17] Senthilkumar V, Vickraman P, Jayachandran M and Sanjeeviraja C 2010 Vacuum 84864

[18] Ali K, Khan S A and Jafri M Z 2014 Nanoscale Res. Lett. 9 175

[19] Terzini E, Thilakan P and Minarini C 2000 Mater. Sci. Eng. B77 110

[20] You Y Z, Kim Y S, Choi D H, Jang H S, Lee J and Kim H D 2008 Mater. Chem. Phys. 107444

[21] Hao L, Diao X, Xu H, Gu B and Wang T 2008 Appl. Surf. Sci. 2543504

[22] Vergne C, Buchheit O, Eddoumy F, Sorrenti E, Martino J D and Ruch D 2011 J. Eng. Mater. Technol. 1333

[23] Kim J S, Ho P K H, Thomas D S, Friend R H, Cacialli F, Bao G W et al 1999 Chem. Phys. Lett. 315312

[24] Mizuhashi M 1980 Thin Sol. Films 7091

[25] Domtau D L, Simiyu J, Ayieta E O, Muthoka B and Mwabora J M 2016 J. Mat. Phys. Chem. 41

[26] Thirumoorthi M and Prakash J 2016 J. Asian Cer. Soc. 4124

[27] Kim H and Gilmore C M 1999 J. Appl. Phys. 866451

[28] Liau Y H, Scherer N F and Rhodes K 2001 J. Phys. Chem. B 1053282

[29] Guillen C and Herrero J 2005 Thin Sol. Films 480 129

[30] Chen Z, Cotterell B and Wang W 2002 Eng. Fract. Mech. 69 597 